\title{
INFLUÊNCIA DO CULTIVO DA CANA-DE-AÇÚCAR E DA MINERALOGIA DA FRAÇÃO ARGILA NAS PROPRIEDADES FÍSICAS DE LATOSSOLOS VERMELHOS ${ }^{(1)}$
}

\author{
José Frederico Centurion $^{(2)}$, Onã da Silva Freddi ${ }^{(3)}$, Ricardo Garcia \\ Aratani $^{(3)}$, Ana Flávia Mangeti Metzner ${ }^{(4)}$, Amauri Nelson \\ Beutler $^{(5)}$ \& Itamar Andrioli ${ }^{(2)}$
}

\begin{abstract}
RESUMO
As atuais técnicas de manejo da cultura da cana-de-açúcar utilizam um vigoroso revolvimento do solo por ocasião do plantio, com o uso de arados, grades pesadas e subsoladores. O objetivo deste trabalho foi avaliar o grau de modificação de algumas propriedades físicas de um Latossolo Vermelho caulinítico (LVd) e de um Latossolo Vermelho caulinítico-oxídico ( $\mathrm{LVdf}$ ) cultivados com cana-de-açúcar e sob mata nativa no município de Jaboticabal (SP), além de comparar as propriedades físicas encontradas em ambos os Latossolos. O delineamento experimental utilizado foi o inteiramente casualizado, em esquema de parcelas subdivididas $4 \times 3$ (manejos e camadas), com quatro repetições. Também foi realizada a análise conjunta entre as propriedades físicas dos Latossolos. Os sistemas de uso foram: cana planta (CP), cana soca de segundo ano (C2), cana soca de quarto ano (C4) e mata nativa (MN). Avaliaram-se a densidade do solo (Ds), a sua porosidade e o diâmetro médio ponderado (DMP) nas camadas de $0-0,10,0,10-0,20$ e $0,20-0,30 \mathrm{~m}$. Os efeitos dos sistemas de uso e manejo sobre os atributos físicos, nas diferentes camadas, foram verificados a partir da análise de variância; quando significativas, as médias foram comparadas pelo teste de Tukey a $5 \%$. A MN do LVdf apresentou maior macroporosidade e menor microporosidade em relação à das áreas cultivadas, mas, para porosidade total e Ds, a MN apresentou diferença apenas para $\mathrm{C} 2 \mathrm{e} \mathrm{C} 4$. $\mathrm{O}$ tempo de cultivo da cana-de-açúcar proporcionou o aumento da Ds e diminuição
\end{abstract}

(1) Recebido para publicação em março de 2006 aprovado em fevereiro de 2007.

(2) Professor Adjunto, Departamento de Solos e Adubos. Faculdade de Ciências Agrárias e Veterinárias, UNESP. Bolsista CNPq. E-mail: jfcentur@fcav.unesp.br

(3) Doutorando da Faculdade de Ciências Agrárias e Veterinárias, Universidade Estadual Paulista - UNESP. Departamento de Solos e Adubos. Via de Acesso Prof. Paulo Donato Castellane s/nº, 14884-900. Jaboticabal, São Paulo, Brasil. Bolsista FAPESP. E-mail: onafreddi@fcav.unesp.br; aratani@fcav.unesp.br

(4) Engenheira-Agrônoma pela FCAV/UNESP. E-mail: anaflavia_mm@yahoo.com.br

(5) Pós-Doutorando do Departamento de Solos e Adubos. Faculdade de Ciências Agrárias e Veterinárias, UNESP. Bolsista FAPESP. E-mail: amaurib@yahoo.com.br 
da macroporosidade em ambos os Latossolos. Entretanto, o maior teor de óxido de Fe no LVdf proporcionou maior porosidade total e menor Ds, e sua macroporosidade permaneceu acima de $0,10 \mathrm{~m}^{3} \mathrm{~m}^{-3} \mathrm{em}$ todos os manejos e camadas. Os sistemas de uso do solo com cana-de-açúcar reduziram a estabilidade de agregados, em relação à mata nativa.

Termos de indexação: Saccharum officinarum, densidade do solo, qualidade física do solo.

\title{
SUMMARY: INFLUENCE OF SUGARCANE CULTIVATION AND CLAY MINERALOGY IN PHYSICAL PROPERTIES OF RHODIC OXISOLS
}

\begin{abstract}
The current sugarcane management techniques employed involve vigorous soil revolvement with ploughs, heavy disks and subsoilers before planting. The aim of this study was to evaluate the degree of modification of some physical properties of a kaolinitic Oxisol $(L V d)$ and a kaolinitic - oxidic Oxisol ( LVdf) under sugarcane and native forest in Jaboticabal county, São Paulo state, Brazil. The experimental design was completely randomized, in a $4 \times 3$ split plot scheme (four managements and three depths), with four replications. The following systems were used: plant sugarcane $(C P)$; second ratoon sugarcane (C2), fourth ratoon cane (C4) and native forest (NF). The soil bulk density (BD), porosity and aggregate stability were evaluated in the $0-0.10 ; 0.10-0.20 ; 0.20-0.30 \mathrm{~m}$ layers. The effects of land use and management systems on the physical attributes at the studied depths were verified by analysis of variance, and significant means were compared by the Tukey's test (5\%). The highest macroporosity and lowest microporosity in relation with the cultivated areas was observed for the LVdf under NF. However, only total porosity and $B D$ in $C 2$ and $C 4$ differed from those in the NF. The longer the sugarcane cultivation time, the higher the BD, and the lower the macroporosity in both Oxisols. Nevertheless, the higher the Fe oxide content in the LVdf resulted in higher total porosity and lower BD, maintaining the porosity above $0.10 \mathrm{~m}^{3} \mathrm{~m}^{3}$ in all management systems and soil layers. The sugarcane cultivation reduced the aggregate stability in relation to the NF.
\end{abstract}

Index terms: Saccharum officinarum, bulk density, soil physical quality.

\section{INTRODUÇÃO}

O cultivo intensivo do solo e seu preparo em condições inadequadas alteram os fatores de crescimento das culturas. Dependendo da intensidade com que ocorrem, essas alterações podem produzir condições limitantes ao crescimento e desenvolvimento dos vegetais, em detrimento da produtividade, além de grandes perdas de solo por erosão hídrica (Cintra et al., 1983).

O intenso preparo do solo para o plantio da canade-açúcar e a utilização constante de cultivadores em condições não ideais de umidade alteram suas propriedades físicas (Byrnes et al., 1982), refletindo em alterações na estrutura do solo, principalmente na camada superficial (Cerri et al., 1991). As modificações que ocorrem na estrutura do solo são evidenciadas por alterações nos valores de densidade do solo, resistência mecânica à penetração, porosidade total, porosidade de aeração, armazenagem e disponibilidade de água às plantas, dinâmica de água na superfície e no seu perfil, assim como a consistência e a máxima compactabilidade do solo (Klein et al., 1998).
O ideal seria o uso e o manejo do solo que estabelecessem uma associação conveniente dessas propriedades, de modo que possibilitasse condições cada vez melhores para o crescimento e desenvolvimento vegetal, promovendo, conseqüentemente, menores perdas de solo e de água e, finalmente, maior produtividade associada à qualidade ambiental (Souza \& Alves, 2003).

Os solos possuem diferenças estruturais que derivam da pedogênese, apresentando diferentes granulometrias, mineralogias e conteúdo de matéria orgânica, que podem vir a ser modificados pelo seu uso e cultivo (Centurion et al., 2004). Em avançado estado de intemperismo, os solos apresentam intensa perda de sílica (dessilicatização), com resultante acúmulo de óxidos insolúveis de $\mathrm{Fe}$ e $\mathrm{Al}$ (Uehara, 1988). A mineralogia da fração argila dos Latossolos é constituída por caulinita, óxidos de $\mathrm{Al}$ (gibbsita), óxidos de $\mathrm{Fe}$ (hematita e goetita) e minerais 2:1 (menores quantidades), combinados em diferentes proporções, porém em estreita associação (Schwertmann \& Herbillon, 1992). Tais minerais são responsáveis pela retenção e distribuição de água, nutrientes, calor e 
gases. Os óxidos de $\mathrm{Fe}$ e $\mathrm{Al}$, ao contrário das argilas silicatadas, apresentam porosidade, plasticidade, expansibilidade e coesão muito maiores - qualidades que se traduzem por boas condições físicas proporcionadas aos solos nos quais são predominantes (Vieira, 1988).

Portanto, a compreensão e a quantificação do impacto do uso e manejo do solo na sua qualidade física são fundamentais no desenvolvimento de sistemas agrícolas sustentáveis (Dexter \& Youngs, 1992). De acordo com Sanchez (1981), avaliações das modificações no solo decorrentes do cultivo deveriam ser feitas, submetendo um solo sob vegetação natural às explorações agrícolas desejadas e analisando suas propriedades periodicamente. Nesse contexto, o objetivo do trabalho foi avaliar a influência do cultivo da cana-deaçúcar e da mineralogia da fração argila em algumas propriedades físicas de dois Latossolos Vermelhos.

\section{MATERIAL E MÉTODOS}

O estudo foi realizado em um Latossolo Vermelho distrófico argiloso A moderado hipoférrico caulinítico relevo suave ondulado (LVd) com $7 \%$ de $^{\mathrm{Fe}_{2}} \mathrm{O}_{3}$ e em um Latossolo Vermelho distroférrico argiloso A moderado caulinítico-oxídico relevo suave ondulado (LVdf) com $27 \%$ de $\mathrm{Fe}_{2} \mathrm{O}_{3}$. As coordenadas geográficas da área experimental são $21^{\circ} 14^{\prime} 01$ " de latitude sul, $48^{\circ} 15^{\prime}$ ' 59 " de longitude oeste, $601 \mathrm{~m}$ de altitude para o LVd e $578 \mathrm{~m}$ para o LVdf, localizada no município de Jaboticabal (SP). O clima, segundo a classificação de Köppen, é mesotérmico de inverno seco (Cwa). Os teores de matéria orgânica e argila dos Latossolos encontram-se no quadro 1.

A área experimental é cultivada com cana-deaçúcar (Saccharum officinarum) desde 1990. No plantio da cana planta ou a cada 5-6 anos, quando da renovação do canavial, o preparo do solo consiste em subsolagem a $50 \mathrm{~cm}$ de profundidade, duas gradagens pesadas (16 discos de 32 polegadas) com profundidade de $25 \mathrm{~cm}$ e abertura de sulcos de $25 \mathrm{~cm}$ de profundidade com sulcador. O plantio da cana-deaçúcar foi efetuado após a colheita da cultura do amendoim, utilizando-se um espaçamento de 1,40 m entre linhas. As adubações anuais são incorporadas por meio de cultivador, a uma profundidade de aproximadamente $0,30 \mathrm{~m}$. A variedade plantada foi a RB 5536. As colheitas sempre foram realizadas manualmente, após a queima da palhada.

Quadro 1. Teores médios de matéria orgânica e argila dos Latossolos Vermelhos submetidos a sistemas de manejos

\begin{tabular}{|c|c|c|c|c|}
\hline \multirow{2}{*}{ Camada } & \multicolumn{4}{|c|}{ Manejo $^{(1)}$} \\
\hline & MN & CP & $\mathrm{C} 2$ & C4 \\
\hline \multirow{2}{*}{\multicolumn{5}{|c|}{$\begin{array}{c}\mathrm{LVd}^{(2)} \\
\mathrm{MO} \\
\mathrm{dm}^{-3}\end{array}$}} \\
\hline & & & & \\
\hline $\begin{array}{r}0-0,10 \\
0,10-0,20 \\
0,20-0,30\end{array}$ & $\begin{array}{l}38,5 \\
24,0 \\
21,5\end{array}$ & $\begin{array}{l}18,5 \\
19,5 \\
17,0\end{array}$ & $\begin{array}{l}14,0 \\
12,5 \\
10,5\end{array}$ & $\begin{array}{l}15,0 \\
14,5 \\
13,5\end{array}$ \\
\hline \multicolumn{5}{|c|}{ Argila } \\
\hline $\begin{array}{r}0-0,10 \\
0,10-0,20 \\
0,20-0,30\end{array}$ & $\begin{array}{l}290 \\
340 \\
390\end{array}$ & $\begin{array}{l}325 \\
335 \\
335\end{array}$ & $\begin{array}{l}420 \\
435 \\
490\end{array}$ & $\begin{array}{l}300 \\
305 \\
305\end{array}$ \\
\hline \multicolumn{5}{|c|}{$\begin{array}{c}\operatorname{LVdf}^{(3)} \\
\mathrm{MO}\end{array}$} \\
\hline $\begin{array}{r}0-0,10 \\
0,10-0,20 \\
0,20-0,30\end{array}$ & $\begin{array}{l}40,0 \\
39,0 \\
37,0\end{array}$ & $\begin{array}{l}28,0 \\
28,0 \\
27,0\end{array}$ & $\begin{array}{l}24,0 \\
23,0 \\
18,0\end{array}$ & $\begin{array}{l}24,0 \\
22,0 \\
21,0\end{array}$ \\
\hline \multicolumn{5}{|c|}{ Argila } \\
\hline $\begin{array}{r}0-0,10 \\
0,10-0,20 \\
0,20-0,30\end{array}$ & $\begin{array}{l}491 \\
518 \\
520\end{array}$ & $\begin{array}{l}490 \\
497 \\
504\end{array}$ & $\begin{array}{l}498 \\
521 \\
555\end{array}$ & $\begin{array}{l}475 \\
512 \\
559\end{array}$ \\
\hline
\end{tabular}

(1) MN: mata nativa; CP: cana planta; C2: cana soca de segundo ano; C4: cana soca de quarto ano. ${ }^{(2)}$ LVd: Latossolo Vermelho distrófico caulinítico. ${ }^{(3)}$ LVdf: Latossolo Vermelho distroférrico caulinítico-oxídico. 
O delineamento experimental foi o inteiramente casualizado, em esquema de parcelas subdivididas 4 x 3 (manejos e camadas), com quatro repetições. Também foi realizada a análise conjunta entre as propriedades físicas dos Latossolos.

Os sistemas de uso e manejo adotados foram: cana planta $(\mathrm{CP})$, cana soca de segundo ano (C2), cana soca de quarto ano (C4) e mata nativa (MN) em ambas as áreas. Em março de 2005, após a colheita da cana-deaçúcar, foram coletadas amostras indeformadas, para determinação da macroporosidade, microporosidade, porosidade total, densidade do solo, e amostras de solo, para determinação da sua agregação, nas camadas de $0-0,10 ; 0,10-0,20$ e $0,20-0,30 \mathrm{~m}$. As amostras indeformadas foram obtidas com auxílio de anéis volumétricos de $52,35.10^{-6} \mathrm{~m}^{3}$, para determinação da densidade do solo segundo Blake \& Hartge (1986), da microporosidade por secagem (tensão de 0,006 MPa), em mesa de tensão, da porosidade total segundo Danielson \& Sutherland (1986) e da macroporosidade, obtida por diferença entre a porosidade total e a microporosidade. Para determinação da agregação do solo, foram retiradas quatro amostras de cada área nas três camadas, que foram secas ao ar e peneiradas em malha de 7,93 $\mathrm{mm}$. O processo de tamisagem para cada amostra consistiu na separação de três subamostras de $50 \mathrm{~g}$ cada uma (massa do material úmido), uma para cada jogo de peneiras (repetições 1 e 2 no laboratório, sendo no cálculo final utilizada a média) e uma para determinação da umidade e, assim, calcular a massa da amostra seca. O jogo de peneiras foi constituído pelas malhas de $4 ; 2 ; 1 ; 0,5 ; 0,250 \mathrm{e}$ $0,125 \mathrm{~mm}$. Em cada jogo de peneiras a amostra de agregados com $50 \mathrm{~g}$ foi colocada sobre a peneira de maior malha $(4 \mathrm{~mm})$ com um papel-filtro, para retenção da terra até que ela fosse saturada por capilaridade durante $10 \mathrm{~min}$. Depois de saturado, o papel era retirado com auxílio de uma pisseta com água. Em seguida, o conjunto de peneiras foi colocado em tanque com água e submetido à agitação vertical por 15 min, com 30 oscilações por minuto. O solo retido em cada peneira foi transferido para frascos com auxílio de jatos de água fracos dirigidos ao fundo da peneira e, em seguida, colocado na estufa para secagem $\left(105^{\circ} \mathrm{C}\right.$ durante $\left.24 \mathrm{~h}\right)$, sendo posteriormente pesado. Após obtenção da massa de solo seco de cada classe de agregados (solo retido nas peneiras), calculouse a média entre as duas classes iguais. Posteriormente, as amostras secas foram pesadas, $\mathrm{e}$ os valores de diâmetro médio ponderado (DMP), calculados de acordo com o método apresentado por Kiehl (1979), da seguinte maneira:

$$
\mathrm{DMP}=\sum_{\mathrm{i}=1}^{\mathrm{n}} \text { (xi.wi) }
$$

em que wi é a proporção de cada classe em relação ao total e xi, o diâmetro médio das classes $(\mathrm{mm})$.

Os efeitos dos sistemas de uso e manejo sobre os atributos físicos, nas diferentes camadas estudadas, foram verificados a partir da análise de variância; quando significativas, as médias foram comparadas pelo teste de Tukey a $5 \%$.

\section{RESULTADOS E DISCUSSÃO}

\section{Propriedades físicas do LVd}

Os resultados das análises de variância (Quadro 2) mostram que todas as propriedades físicas do LVd foram influenciadas pelo sistema de manejo e camada, com exceção apenas da microporosidade, que não teve influência dos fatores. A macroporosidade, porosidade total e densidade do solo apresentaram comportamento diferenciado entre os sistemas de manejo e camadas.

A MN apresentou a menor densidade do solo na camada de $0-0,10 \mathrm{~m}$, em relação aos demais tratamentos (Quadro 3). Segundo Assis \& Lanças (2005), tal fato se deve ao maior teor de matéria orgânica nesta camada (Quadro 1), o que favorece a diminuição da densidade do solo, pela sua maior estruturação. O tempo de cultivo da cana-de-açúcar proporcionou aumento na densidade do solo. Observase que a $\mathrm{C} 4$ apresentou as maiores densidades do solo em todas as camadas avaliadas. A densidade do solo foi menor na camada de $0-10 \mathrm{~m}$ em todos os tratamentos, com exceção apenas do CP, que apresentou menor densidade na camada de $0-0,20 \mathrm{~m}$, devido ao preparo mais recente do solo.

A MN apresentou o maior volume de macroporos nas camadas de 0-0,10 e 0,20-0,30 m (Quadro 3). Já na camada de $0,10-0,20$ m ela mostrou maior quantidade de macroporos, em relação a C2 e C4. Observa-se que o cultivo da cana-de-açúcar provocou diminuição da macroporosidade do LVd, independentemente do ano de cultivo.

Os valores de macroporosidade foram maiores, com diferenças estatisticamente significativas, nas camadas de $0-0,10 \mathrm{~m}$ para $\mathrm{MN}$ e C4, 0-0,20 m para CP e 0-0,10 m em relação apenas à camada de 0,20 0,30 para C2 (Quadro 3). A maior macroporosidade observada na camada de 0-10 para MN se deve ao maior teor de matéria orgânica neste sistema, refletindo em melhorias na estruturação do solo; já para $\mathrm{C} 4$, provavelmente o tráfego de máquinas tenha provocado diminuição da macroporosidade abaixo desta camada, o que não foi observado em $\mathrm{CP}$, devido ao intenso preparo do solo para plantio, e em C2, em razão do tempo de instalação da cultura. Segundo Borges et al. (1999), a redução da macroporosidade nos solos cultivados decorre do aumento da compactação, que é evidenciada pelo aumento da densidade do solo. No que se refere à porosidade de aeração, considerando que é apenas nos macroporos que ocorre a circulação de ar, observa-se que na camada de $0,20-0,30 \mathrm{~m}$ na $\mathrm{CP}$ e $\mathrm{C} 2$ e abaixo da camada de $0-0,10 \mathrm{~m}$ na $\mathrm{C} 4$ ocorreram valores de macroporosidade inferiores ao 
Quadro 2. Resumo da análise de variância para as propriedades físicas do solo Latossolo Vermelho distrófico caulinítico ( $\mathrm{LVd})$, envolvendo sistemas de manejo (MJ), camadas (CM) e interações (MJxPF)

\begin{tabular}{|c|c|c|c|c|c|c|}
\hline \multirow{2}{*}{$\begin{array}{l}\text { Propriedade } \\
\quad \text { física }^{(1)}\end{array}$} & \multirow[b]{2}{*}{ Média geral } & \multirow[b]{2}{*}{$\mathrm{CV}_{1}(\%)$} & \multirow[b]{2}{*}{$\mathrm{CV}_{2}(\%)$} & \multicolumn{3}{|c|}{ Quadrado médio ${ }^{(2)}$} \\
\hline & & & & MJ & $\mathbf{C M}$ & $\mathbf{M J x} \mathbf{C M}$ \\
\hline Macro & 0,133 & 20,37 & 16,04 & $0,034 * *$ & $0,012 * *$ & $0,002 * *$ \\
\hline Micro & 0,354 & 5,23 & 6,10 & $0,002^{\mathrm{ns}}$ & $0,001^{\mathrm{ns}}$ & $0,001^{\mathrm{ns}}$ \\
\hline $\mathrm{PT}$ & 0,487 & 5,80 & 5,45 & $0,030 * *$ & $0,008 * *$ & $5,852 * *$ \\
\hline Ds & 1,301 & 5,13 & 4,48 & $0,212^{* *}$ & $0,148^{* *}$ & $0,025^{* *}$ \\
\hline DMP & 3,904 & 9,91 & 12,20 & $18,499 * *$ & $3,990 * *$ & $0,425^{\mathrm{ns}}$ \\
\hline
\end{tabular}

\footnotetext{
(1) Macro: macroporosidade; Micro: microporosidade; PT: porosidade total; Ds: densidade do solo e DMP: diâmetro médio ponderado. (2) **, * F significativo a 1 e $5 \%$, respectivamente. ${ }^{\text {ns }}$ não-significativo. $\mathrm{CV}_{1}$ e $\mathrm{CV}_{2}$ são os coeficientes de variação do fator principal (manejo) e secundário (camada), respectivamente.
}

Quadro 3. Propriedades físicas do Latossolo Vermelho caulinítico (LVd) submetido a sistemas de manejos e camadas

\begin{tabular}{|c|c|c|c|c|}
\hline \multirow{2}{*}{ Camada } & \multicolumn{4}{|c|}{ Propriedade física do solo(1) } \\
\hline & Macro & Micro & PT & Ds \\
\hline & & & \\
\hline $\mathrm{m}$ & + & $-m^{3} m^{-3}$ & - & $\mathrm{Mg} \mathrm{m}^{-3}$ \\
\hline $0-0,10$ & $0,27 \mathrm{Aa}$ & 0,35 & $0,62 \mathrm{Aa}$ & $1,03 \mathrm{Bc}$ \\
\hline $0,10-0,20$ & $0,18 \mathrm{Ba}$ & 0,33 & $0,52 \mathrm{Ba}$ & $1,29 \mathrm{Ab}$ \\
\hline $0,20-0,30$ & $0,19 \mathrm{Ba}$ & 0,33 & $0,50 \mathrm{Ba}$ & $1,26 \mathrm{Ac}$ \\
\hline \multicolumn{5}{|c|}{ Cana planta } \\
\hline $0-0,10$ & $0,13 \mathrm{Ab}$ & 0,35 & $0,47 \mathrm{ABb}$ & $1,17 \mathrm{Bb}$ \\
\hline $0,10-0,20$ & $0,15 \mathrm{Aab}$ & 0,35 & $0,50 \mathrm{Aa}$ & $1,13 \mathrm{Bc}$ \\
\hline $0,20-0,30$ & $0,08 \mathrm{Bb}$ & 0,37 & $0,45 \mathrm{Bbc}$ & $1,41 \mathrm{Ab}$ \\
\hline \multicolumn{5}{|c|}{ Cana soca de $2^{\circ}$ ano } \\
\hline $0-0,10$ & $0,14 \mathrm{Ab}$ & 0,37 & $0,52 \mathrm{Ab}$ & $1,21 \mathrm{Bb}$ \\
\hline $0,10-0,20$ & $0,12 \mathrm{ABb}$ & 0,39 & $0,50 \mathrm{Aa}$ & $1,30 \mathrm{ABb}$ \\
\hline $0,20-0,30$ & 0,09 $\mathrm{Bb}$ & 0,40 & $0,49 \mathrm{Aab}$ & $1,34 \mathrm{Abc}$ \\
\hline \multicolumn{5}{|c|}{ Cana soca de $4^{\circ}$ ano } \\
\hline $0-0,10$ & $0,12 \mathrm{Ab}$ & 0,34 & $0,46 \mathrm{Ab}$ & $1,39 \mathrm{Ba}$ \\
\hline $0,10-0,20$ & $0,08 \mathrm{Bc}$ & 0,34 & $0,41 \mathrm{Ab}$ & $1,53 \mathrm{Aa}$ \\
\hline $0,20-0,30$ & $0,07 \mathrm{Bb}$ & 0,34 & $0,41 \mathrm{Ac}$ & $1,56 \mathrm{Aa}$ \\
\hline $\mathrm{CV}(\%)$ & 17,2 & 5,9 & 5,5 & 4,7 \\
\hline
\end{tabular}

Macro = macroporosidade; Micro = microporosidade; $\mathrm{PT}=$ porosidade total; $\mathrm{Ds}=$ densidade do solo.

${ }^{(1)}$ Médias seguidas pela mesma letra não diferem estatisticamente pelo teste de Tukey a $5 \%$. Letras minúsculas referem-se à comparação de tratamentos numa mesma camada e maiúsculas comparam médias de camadas de um mesmo tratamento.

limite de $0,10 \mathrm{~m}^{3} \mathrm{~m}^{-3}$, considerado por Erickson (1982) como o mínimo de poros de aeração para a maioria das culturas.
Não houve diferença estatística para microporosidade entre as camadas e os manejos estudados no LVd (Quadro 3). Segundo Silva \& Kay (1997), a 
microporosidade do solo é fortemente influenciada pela textura e pelo teor de $\mathrm{C}$ orgânico e muito pouco influenciada pelo aumento da densidade do solo, originada do tráfego de máquinas, implementos, etc.

De acordo com os resultados obtidos em relação à agregação do solo (Figura 1a), observou-se que o maior valor de diâmetro médio ponderado (DMP) foi encontrado para o solo sob MN, que diferiu das áreas cultivadas. Dentre os sistemas cultivados com canade-açúcar, C4 apresentou o menor DMP, quando comparado aos demais. A maior estabilidade dos agregados da mata nativa deve-se, entre outros fatores, ao contínuo fornecimento de material orgânico, que serve como fonte de energia para a atividade microbiana, que atua como agente de estabilização dos agregados (Campos et al., 1995). Além desse aspecto, pode-se salientar o efeito físico das raízes das árvores nas áreas sob mata natural, que atuam na formação, na manutenção e no tamanho dos agregados do solo (Silva et al., 1998). O menor DMP nos sistemas de uso com cana-de-açúcar ocorre porque, além do efeito destrutivo na estrutura do solo pelas operações de preparo e cultivo anual (Corrêa, 2002), foi realizada a queima da palhada antes da colheita, reduzindo, portanto, o teor de MO, o que também foi verificado por Ceddia et al. (1999). Além disso, o revolvimento do solo para o plantio aumenta o contato do ar com a $\mathrm{MO}$, acelerando sua oxidação e decomposição, refletindo em decréscimo do seu teor ao longo dos anos (Góes et al., 2005) e, conseqüentemente, do DMP. Verificouse que $\mathrm{CP}$ e C2 não diferiram entre si, apresentando maiores valores de DMP quando comparados a $\mathrm{C} 4$. Segundo Góes et al. (2005), esse resultado pode ser atribuído ao maior efeito desagregador do cultivador no tratamento C4. Analisando o DMP em diferentes camadas (Figura 1b), nota-se que, independentemente do manejo, as camadas do solo de $0-0,10$ e $0,10-0,20 \mathrm{~m}$ apresentaram maiores DMP em relação à camada de 0,20-0,30 m. Provavelmente o DMP da camada de $0,10-0,20 \mathrm{~m}$, que apresentou menor conteúdo de MO (Quadro 1) e maior densidade em relação à camada superficial do solo, tenha sido igual ao valor encontrado na camada de $0-0,10 \mathrm{~m}$, devido à utilização anual do cultivador, causando compressão das partículas do solo, sem, entretanto, ocorrerem os mecanismos que contribuem para a estabilização desses torrões, não apresentando as qualidades positivas de um agregado (Silva et al., 2000). Esse tipo de agregado, segundo Horn et al. (1995), possui menor grau de resistência interna, o que causa a deterioração da estrutura do solo, formando agregados grandes, porém densos e fracos, com poucos poros interagregados e de menor diâmetro.

\section{Propriedades físicas do LVdf}

As análises de variância das propriedades físicas do LVdf demonstram que a macroporosidade, microporosidade, porosidade total, densidade e agregação do solo apresentaram efeitos isolados para o manejo e para as diferentes camadas, não ocorrendo interação dos fatores (Quadro 4).

Os maiores valores de densidade do solo foram encontrados para C2 e C4, que não diferiram entre si, todavia diferiram da $\mathrm{MN}$ e $\mathrm{CP}$ (Quadro 5). A diferença esperada entre C2 e C4 não foi observada provavelmente devido à utilização do cultivador após a colheita da cana-de-açúcar, para rompimento de possíveis camadas compactadas e deposição e incorporação de adubo. A menor densidade encontrada na MN pode ser explicada pela maior quantidade de MO e ausência do tráfego de máquinas agrícolas, concordando com resultados obtidos por Bertol et al. (2004) e Silva \& Kay (1997). Entretanto, a densidade
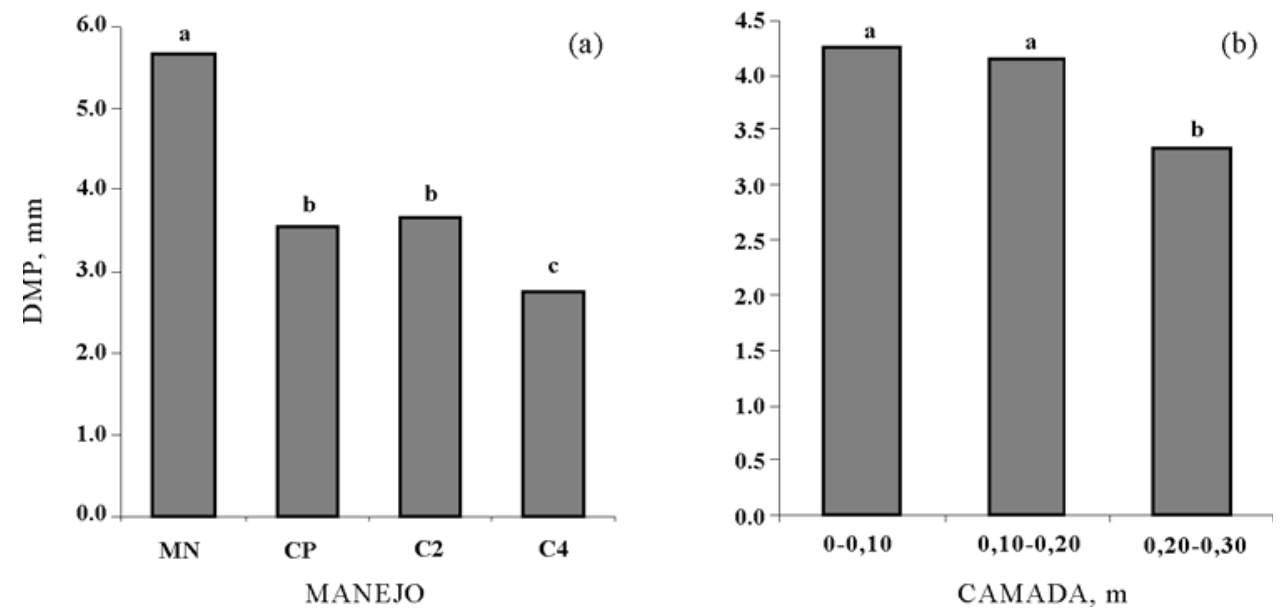

Figura 1. Valores de diâmetro médio ponderado (DMP) de agregados do Latossolo Vermelho caulinítico (LVd) submetido a diferentes manejos (a), utilizando o valor médio da camada de 0-0,30 m, e camadas (b), usando o valor médio de todos os manejos. MN: mata nativa; CP: cana planta; C2: cana soca de segundo ano; $\mathrm{C} 4$ : cana soca de quarto ano. Médias seguidas de mesma letra não diferem estatisticamente pelo teste de Tukey a $5 \%$. 
do solo encontrada na CP foi semelhante à da MN, em razão do recente preparo e sulcação do solo para plantio da cana-de-açúcar (Quadro 5).

Os menores valores de macroporosidade (Quadro 5) foram encontrados em $\mathrm{C} 2$ e C4, que não demonstraram diferença entre si. Esse resultado pode ser explicado pelo aumento da compactação do solo, que é evidenciada pelo aumento de sua densidade (Borges et al., 1999). Mesmo assim, estes tratamentos mostraram macroporosidade média acima de $0,10 \mathrm{~m}^{3} \mathrm{~m}^{-3}$ em todos os manejos e camadas (Quadro 5), indicando que as condições de aeração foram adequadas para as raízes das plantas e revelando que, mesmo sob elevados potenciais da água no solo, a difusão de $\mathrm{O}_{2}$ às raízes não é impeditiva, concordando assim com Tormena et al. (2004). Isso indica que a utilização do cultivador anualmente no LVdf, mesmo na cana soca de 4 anos, proporcionou boas condições de aeração do solo.
Os maiores valores de microporosidade (Quadro 5) foram apresentados pelas áreas cultivadas com canade-açúcar, o que pode ser justificado pelo aumento da densidade do solo e pela diminuição da macroporosidade. A porosidade total observada na MN e CP foi semelhante, provavelmente, pelo excessivo revolvimento do solo para instalação da cultura; entretanto, a porosidade total da $\mathrm{MN}$ foi maior quando comparada à de C2 e C4 (Quadro 5).

$\mathrm{O}$ volume de macroporos, microporos e poros totais foi influenciado pelo cultivo e tempo de cultivo da canade-açúcar, em decorrência da alteração ocorrida em sua densidade (Cintra et al., 1983; Bertol et al., 2004). Esse comportamento, provavelmente, foi reflexo do revolvimento provocado pelo preparo do solo para a CP e pela utilização do cultivador após cada colheita para $\mathrm{C} 2$ e $\mathrm{C} 4$.

Considerando-se a média de todos os manejos, as maiores macroporosidade e porosidade total foram

Quadro 4. Resumo da análise de variância para as propriedades físicas do Latossolo Vermelho distroférrico caulinítico-oxídico (LVdf), envolvendo sistemas de manejo (MJ), camadas (CM) e interações (MJxCM)

\begin{tabular}{|c|c|c|c|c|c|c|}
\hline \multirow{2}{*}{$\begin{array}{l}\text { Propriedade } \\
\text { física }^{(1)}\end{array}$} & \multirow[b]{2}{*}{ Média geral } & \multirow[b]{2}{*}{$\mathrm{CV}_{1}(\%)$} & \multirow[b]{2}{*}{$\mathrm{CV}_{2}(\%)$} & \multicolumn{3}{|c|}{ Quadrado médio ${ }^{(2)}$} \\
\hline & & & & MJ & CM & $\mathbf{M J x} \mathbf{C M}$ \\
\hline Macro & 0,195 & 21,23 & 18,97 & $0,056 * *$ & $0,042 * *$ & $0,003^{\mathrm{ns}}$ \\
\hline Micro & 0,348 & 8,39 & 6,64 & $0,019 * *$ & $0,016^{* *}$ & $0,001^{\mathrm{ns}}$ \\
\hline $\mathrm{PT}$ & 0,542 & 6,69 & 4,56 & $0,011^{* *}$ & $0,007 * *$ & $0,001^{\mathrm{ns}}$ \\
\hline Ds & 1,196 & 8,33 & 9,12 & $0,214^{* *}$ & $0,195^{* *}$ & $0,015^{\mathrm{ns}}$ \\
\hline DMP & 4,026 & 5,31 & 8,54 & $15,388 * *$ & $0,577^{*}$ & $0,289^{\mathrm{ns}}$ \\
\hline
\end{tabular}

(1) Macro: macroporosidade; Micro: microporosidade; PT: porosidade total; Ds: densidade do solo e DMP: diâmetro médio ponderado. $(2) * *, *$ F significativo a 1 e $5 \%$, respectivamente; ${ }^{n}$ não-significativo; $\mathrm{CV}_{1}$ e $\mathrm{CV}_{2}$ são os coeficientes de variação do fator principal (manejo) e secundário (camada), respectivamente.

Quadro 5. Propriedades físicas do Latossolo Vermelho caulinítico-oxídico (LVdf) submetido a sistemas de manejo na camada de $0-0,30 \mathrm{~m}$

\begin{tabular}{|c|c|c|c|c|}
\hline \multirow{2}{*}{ Manejo } & \multicolumn{4}{|c|}{ Propriedade física do solo } \\
\hline & Macro & Micro & $\mathbf{P T}$ & Ds \\
\hline & 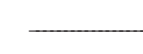 & $-\mathrm{m}^{3} \mathrm{~m}^{-3}$ & $\underline{-1}$ & $\mathrm{Mg} \mathrm{m}^{-3}$ \\
\hline $\mathrm{MN}$ & $0,286 \mathrm{a}$ & $0,295 \mathrm{c}$ & $0,576 \mathrm{a}$ & $1,08 \mathrm{~b}$ \\
\hline $\mathrm{CP}$ & $0,217 \mathrm{~b}$ & $0,343 \mathrm{~b}$ & $0,561 \mathrm{ab}$ & $1,12 \mathrm{~b}$ \\
\hline $\mathrm{C} 2$ & $0,144 \mathrm{c}$ & 0,386 a & $0,521 \mathrm{bc}$ & $1,29 \mathrm{a}$ \\
\hline $\mathrm{C} 4$ & $0,146 \mathrm{c}$ & $0,367 \mathrm{ab}$ & $0,513 \mathrm{c}$ & $1,33 \mathrm{a}$ \\
\hline CV (\%) & 20,6 & 8,4 & 6,7 & 10,6 \\
\hline
\end{tabular}

Macro = macroporosidade; Micro $=$ microporosidade; $\mathrm{PT}=$ porosidade total; $\mathrm{Ds}=$ densidade do solo.

MN: mata nativa; CP: cana planta; C2: cana soca de segundo ano; C4: cana soca de quarto ano. Médias seguidas pelas mesmas letras na coluna não diferem estatisticamente entre si pelo teste de Tukey a $5 \%$. 
observadas na camada de 0-0,10 m (Quadro 6), corroborando resultados obtidos por Cruz et al. (2003), que avaliaram as propriedades físicas de um Argissolo Vermelho submetido a diferentes sistemas de manejo e constataram que o solo sob sistemas convencionais apresentou maior porosidade total e macroporosidade na camada de 0-0,10 m. Segundo esses autores, tal resultado pode ser justificado pela diminuição da densidade do solo em decorrência do seu preparo, possibilitando, assim, maior quantidade de poros, além da contribuição da MO, principalmente da MN. Houve aumento da microporosidade em profundidade, acompanhando a diminuição da macroporosidade proporcionada pelo aumento da densidade do solo, comprovando que, no processo de compactação, ocorre a transformação de macro em microporos (Klein \& Libardi, 2002).

Analisando o DMP em diferentes manejos (Figura 2a), pôde-se verificar que o maior valor foi encontrado em MN, que diferiu estatisticamente dos demais. Os tratamentos $\mathrm{C} 2$ e $\mathrm{C} 4$ mostraram os menores valores de DMP, não diferindo entre si. Silva et al. (1998) observaram que solos sob cerrado nativo dispunham de agregados maiores, por apresentarem maior conteúdo de MO quando comparados às áreas submetidas ao preparo convencional do solo para incorporação de diferentes culturas de cobertura antes do plantio do milho. Segundo Angers (1992), o maior DMP na mata nativa se deve, principalmente, à permanência de resíduos orgânicos na superfície do solo, os quais se decompõem pela ação de microrganismos, resultando na formação de inúmeros compostos importantes na cimentação e estabilização dos agregados. Freire (1972) relatou que o freqüente uso de sistemas de cultivo diminuiu a estabilidade dos agregados, causando sua destruição e, portanto, o menor valor de DMP. Em profundidade (Figura 2b), pôde-se verificar que o maior DMP foi encontrado na camada de $0,10-0,20 \mathrm{~m}$ e o menor, na de $0,20-0,30 \mathrm{~m}$, comportamento semelhante ao apresentado pelo LVd. Contudo, para o LVdf o DMP da camada de 0-10 m não diferiu estatisticamente daquele das camadas de $0,10-0,20$ e $0,20-0,30 \mathrm{~m}$.

\section{Análise conjunta das propriedades físicas}

Os óxidos de $\mathrm{Fe}$ e de $\mathrm{Al}$ são importantes na agregação do solo, uma vez que, sendo considerados agentes desorganizadores em nível microscópico, com aumento dos seus teores, as partículas tendem a um arranjo mais casualizado e a estrutura tende a granular (Resende, 1985), influenciando as propriedades físicas do solo (Pedrotti et al., 2003). Pela análise conjunta dos resultados dos experimentos, observou-se que o LVd, considerando-se a média de todos os manejos e camadas, apresentou a menor macroporosidade e porosidade total e a maior densidade do solo, diferindo assim dos resultados obtidos para o LVdf, em que se encontrou a menor densidade do solo (Quadro 7), não ocorrendo diferença para a microporosidade e o DMP. Segundo Ferreira et al. (1999a), os Latossolos cauliníticos, em razão do ajuste face a face das placas de caulinita, desenvolvem um plasma denso, que lhes confere valores mais elevados de densidade do solo; assim, aos maiores teores de caulinita corresponderão Latossolos com os maiores valores de densidade. Os autores ainda afirmaram que a macroporosidade está correlacionada


e com o teor de argila, o que pôde explicar a maior macroporosidade observada no LVd, que mostrou maior quantidade de argila em relação ao LVdf (Quadro 1); Pedrotti et al. (2003) demonstraram haver correlação negativa da macroporosidade com o aumento da caulinita na fração argila dos solos e correlação positiva com o aumento da gibbsita. Para Ferreira et al. (1999b), a distribuição dos grãos de quartzo em relação ao plasma é porfirogrânica, isto é, os grãos estão envoltos num plasma denso, contínuo,

Quadro 6. Propriedades físicas do Latossolo Vermelho caulinítico-oxídico (LVdf) em diferentes camadas, utilizando-se a média dos sistemas de manejo mata nativa, cana planta e cana soca de segundo e quarto ano

\begin{tabular}{|c|c|c|c|c|}
\hline \multirow[b]{2}{*}{ Camada } & \multicolumn{4}{|c|}{ Propriedade física do solo(1) } \\
\hline & Macro & Micro & PT & Ds \\
\hline \multicolumn{5}{|c|}{ Mata nativa } \\
\hline $0-0,10$ & $0,252 \mathrm{a}$ & $0,314 \mathrm{c}$ & $0,567 \mathrm{a}$ & $1,07 \mathrm{~b}$ \\
\hline $0,10-0,20$ & $0,181 \mathrm{~b}$ & $0,352 \mathrm{~b}$ & $0,531 \mathrm{~b}$ & $1,24 \mathrm{a}$ \\
\hline $0,20-0,30$ & $0,154 \mathrm{~b}$ & $0,377 \mathrm{a}$ & $0,530 \mathrm{~b}$ & $1,30 \mathrm{a}$ \\
\hline CV (\%) & 19,8 & 6,7 & 4,7 & 10,6 \\
\hline
\end{tabular}

Macro = macroporosidade Micro $=$ microporosidade $; \mathrm{PT}=$ porosidade total; $\mathrm{Ds}=$ densidade do solo.

${ }^{(1)}$ Médias seguidas pelas mesmas letras na coluna não diferem estatisticamente entre si pelo teste de Tukey a $5 \%$. 

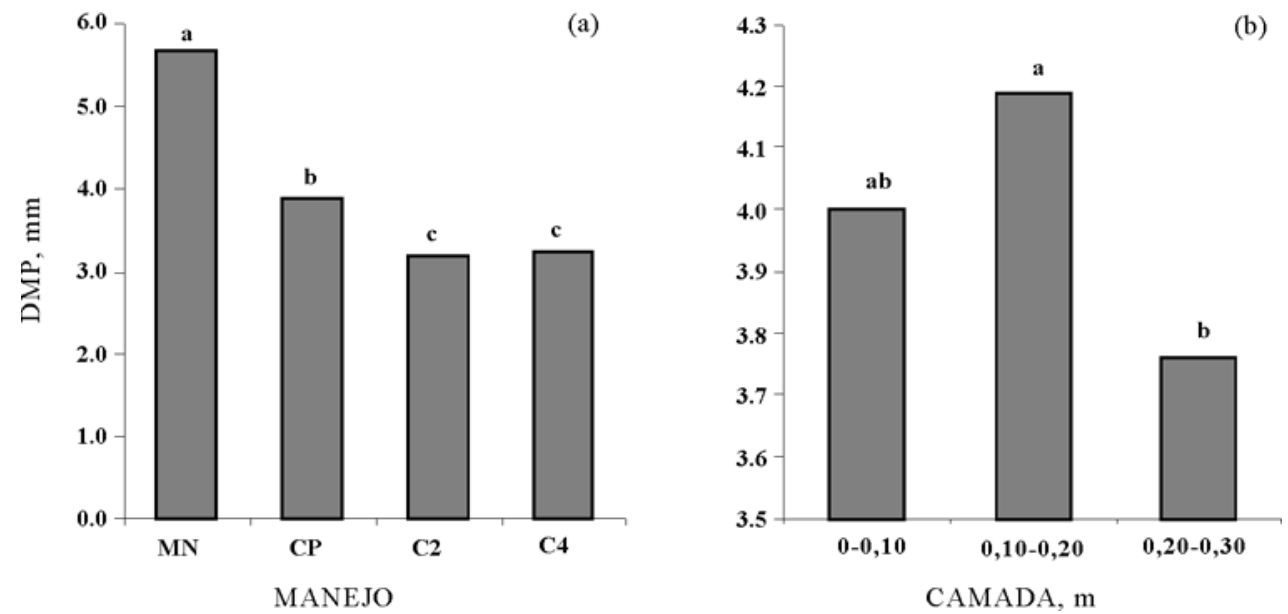

Figura 2. Valores de diâmetro médio ponderado (DMP) de agregados do Latossolo Vermelho cauliníticooxídico (LVdf) submetido a diferentes manejos (a), utilizando o valor médio da camada de 0-0,30 m, e camadas (b), usando o valor médio de todos os manejos. MN: mata nativa; CP: cana planta; C2: cana soca de segundo ano; C4: cana soca de quarto ano. Médias seguidas de mesma letra não diferem estatisticamente pelo teste de Tukey a $5 \%$.

Quadro 7. Comparação entre as propriedades físicas do Latossolo Vermelho caulinítico (LVd) e do Latossolo Vermelho caulinítico-oxídico (LVdf) utilizando-se a média de quatro sistemas de manejo (mata nativa, cana planta e cana soca de segundo e quarto ano) e três camadas $(0-0,10 ; 0-10-0,20$ e 0,20-0,30 m)

\begin{tabular}{|c|c|c|c|c|c|}
\hline \multirow{2}{*}{ Latossolo ${ }^{(1)}$} & \multicolumn{5}{|c|}{ Propriedade física do solo } \\
\hline & Macro & Micro & $\mathbf{P T}$ & Ds & DMP \\
\hline & \multicolumn{3}{|c|}{$-\mathrm{m}^{3} \mathrm{~m}^{-3}$} & $\mathrm{Mg} \mathrm{m}^{-3}$ & $\mathrm{~mm}$ \\
\hline LVd & $0,13 \mathrm{~b}$ & $0,35 \mathrm{a}$ & $0,49 \mathrm{~b}$ & $1,30 \mathrm{a}$ & $3,90 \mathrm{a}$ \\
\hline LVdf & $0,19 \mathrm{a}$ & $0,35 \mathrm{a}$ & $0,54 \mathrm{a}$ & $1,20 \mathrm{~b}$ & $4,02 \mathrm{a}$ \\
\hline CV (\%) & 29,9 & 8,71 & 7,05 & 10,35 & 13,19 \\
\hline
\end{tabular}

${ }^{(1)}$ Médias seguidas da mesma letra na coluna não diferem estatisticamente pelo teste de Tukey a $5 \%$. Macro = macroporosidade; Micro = microporosidade; $\mathrm{PT}=$ porosidade total; $\mathrm{Ds}=$ densidade do solo; $\mathrm{DMP}=$ diâmetro médio ponderado. ${ }^{(2)} \mathrm{LVd}_{\mathrm{V}} 7 \%$ de $\mathrm{Fe}_{2} \mathrm{O}_{3}$; LVdf: $27 \%$ de $\mathrm{Fe}_{2} \mathrm{O}_{3}$.

com pouca tendência ao desenvolvimento de microestrutura, razão do ajuste face a face das placas de caulinita, e o modelo caulinítico implica o desenvolvimento de macroestrutura do tipo em blocos, devendo originar Latossolos com maior densidade do solo, maior proporção de poros pequenos e menor permeabilidade. Segundo Beutler et al. (2002), a maior retenção de água em baixas tensões para o Latossolo Vermelho eutroférrico oxídico em relação ao Latossolo Vermelho distrófico caulinítico deveu-se, entre outros fatores, à mineralogia oxídica da fração argila, que promove a formação de micropeds (microagregados) arredondados com menos de $1 \mathrm{~mm}$, promovendo maior proporção de poros grandes e menor densidade do solo.

Chagas et al. (1997) também relataram que solos com elevado conteúdo de caulinita na fração argila apresentaram alta densidade, menor porosidade total e macroporosidade quando comparados com outros solos oxídicos. Centurion et al. (2004), avaliando atributos físicos de um Latossolo Vermelho distrófico caulinítico e de um Latossolo Vermelho eutroférrico oxídico sob diferentes sistemas de uso, observaram que o Latossolo caulinítico apresentou maior densidade e microporosidade e menor porosidade total e macroporosidade.

\section{CONCLUSÕES}

1. O tempo de cultivo da cana-de-açúcar proporcionou aumento da densidade do solo e diminuição da macroporosidade e porosidade total em ambos os Latossolos. 
2. A microporosidade não foi alterada com o cultivo da cana-de-açúcar para o Latossolo Vermelho caulinítico; entretanto, para o Latossolo Vermelho caulinítico-oxídico o tempo de cultivo da cana-de-açúcar aumentou a quantidade de microporos.

3. O Latossolo Vermelho caulinítico apresentou valores de macroporosidade abaixo de $0,10 \mathrm{~m}^{3} \mathrm{~m}^{-3}$ para a camada de $0,20-0,30 \mathrm{~m}$ da cana planta e cana soca de segundo ano e abaixo da camada de $0-0,10 \mathrm{~m}$ da cana soca de quarto ano, limitante à aeração do solo.

4. A maior quantidade de óxido de Fe no Latossolo Vermelho caulinítico-oxídico proporcionou maior porosidade total e menor densidade do solo; sua macroporosidade permaneceu acima de $0,10 \mathrm{~m}^{3} \mathrm{~m}^{-3}$, considerando-se a média de todos os manejos e camadas, indicando melhores condições de aeração.

5. Os sistemas de uso do solo com cana-de-açúcar reduziram a estabilidade de agregados em relação à mata nativa.

\section{LITERATURA CITADA}

ANGERS, D.A. Changes in soil aggregation and organic carbon under corn and alfafa. Soil Sci. Soc. Am. J., 56:1244-1249, 1992.

ASSIS, R.L. \& LANÇAS, K.P. Avaliação da compressibilidade de um Nitossolo Vermelho distroférrico sob sistema plantio direto, preparo convencional e mata nativa. R. Bras.Ci. Solo, 29:507-514, 2005.

BERTOL, I.; ALBUQUERQUE, J.A.; LEITE, D. \& ZOLDAN JUNIOR, W.A. Propriedades físicas do solo sob preparo convencional e semeadura direta em rotação e sucessão de culturas, comparadas às do campo nativo. R. Bras. Ci. Solo, 28:155-163, 2004.

BEUTLER, A.N.; CENTURION, J.F.; SOUZA, Z.M.; ANDRIOLI, I. \& ROQUE, C.G. Retenção de água em dois tipos de Latossolos sob diferentes usos. R. Bras. Ci. Solo, 26:829-834, 2002.

BLAKE, G.R. \& HARTGE, K.H. Bulk density. In: KLUTE, A., ed. Methods of soil analysis. Madison, American Society of Agronomy, 1986. p.377-382.

BORGES, A.L.; KIEHL, J.C. \& SOUZA, L.S. Alteração de propriedades físicas e atividade microbiana de um Latossolo Amarelo álico após cultivo com fruteiras perenes e mandioca. R. Bras. Ci. Solo, 23:1019-1025, 1999.

BYRNES, W.R.; McFEE, W.W. \& STEINHARDT, G.C. Soil compaction related to agricultural and construction operations. West Lafayette, Purdue University, 1982. $164 \mathrm{p}$.

CAMPOS, B.C.; REINERT, D.J.; NICOLODI, R.; RUEDELL, J. \& PETRERE, C. Estabilidade estrutural de um Latossolo Vermelho-Escuro distrófico após sete anos de rotação de culturas e sistemas de manejo de solo. R. Bras. Ci. Solo, 19:121-126, 1995.
CEDDIA, M.B.; ANJOS, L.H.C.; LIMA, E.; RAVELLI NETO, A. \& SILVA, L.A. Sistemas de colheita da cana-de-açúcar e alterações nas propriedades físicas de um solo Podzólico Amarelo no Estado do Espírito Santo. Pesq. Agropec. Bras., 34:1467-1473, 1999.

CENTURION, J.F.; BEUTLER, A.N. \& SOUZA, Z.M. Physical attributes of kaolinitic and oxidic oxisols resulting from different usage systems. Braz. Arch. Biol. Technol., 47:725-732, 2004

CERRI, C.C.; FELLER, C. \& CHAUVEL, A. Evolução das principais propriedades de um Latossolo VermelhoEscuro após desmatamento e cultivo por doze e cinqüenta anos com cana-de-açúcar. Cah. Orston, Ser. Pédol, 26:37-50, 1991.

CINTRA, F.L.D.; MIELNICZUK, J. \& SCOPEL, I. Caracterização do impedimento mecânico em um Latossolo Roxo do Rio Grande do Sul. R. Bras. Ci. Solo, 7:323-327, 1983.

CORRÊA, J.C. Efeito de sistemas de cultivo na estabilidade de agregados de um Latossolo Vermelho-Amarelo em Querência, MT. Pesq. Agropec. Bras., 37:203-209, 2002.

CHAGAS, C.S.; CURI, N.; DUARTE, M.N.; MOTTA, P.E.F. \& LIMA, J.M. Orientação das camadas de rochas metapelíticas pobres na gênese de Latossolos sob cerrado. Pesq. Agropec. Bras., 32:539-548, 1997.

CRUZ, A.C.R.; PAULETTO, E.A.; FLORES, C.A. \& SILVA, J.R. Atributos físicos e carbono orgânico de um Argissolo Vermelho sob sistemas de manejos. R. Bras. Ci. Solo, 27:1105-1112, 2003.

DANIELSON, R.E. \& SUTHERLAND, P.L. Porosity. In: KLUTE, A., ed. Methods of soil analysis. Madison, American Society of Agronomy, 1986. p.443-461.

DEXTER, A.R. \& YOUNGS, I.M. Soil physics toward 2000. Soil Till. Res., 24:101-106, 1992.

ERICKSON, A.E. Tillage effects on soil aeration. In: PREDICTING TILLAGE EFFECTS ON SOIL PHYSICAL PROPERTIES AND PROCESSES, Madison, 1982. Proceedings. Madison, American Society of Agronomy, 1982. p.91-104.

FERREIRA, M.M.; FERNANDES, B. \& CURI, N. Influência da mineralogia da fração argila nas propriedades físicas de Latossolos da Região Sudeste do Brasil. R. Bras. Ci. Solo, 23:515-524, 1999a.

FERREIRA, M.M.; FERNADES, B. \& CURI, N. Mineralogia da fração argila e estrutura de Latossolos da Região Sudeste do Brasil. R. Bras. Ci. Solo, 23:507-514, 1999 b.

FREIRE, W.J. O efeito do preparo sobre a agregação do solo. Eng. Agric., 1:25-30, 1972.

GÓES, G.B.; GREGGIO, T.C.; CENTURION, J.F.; BEUTLER, A.N. \& ANDRIOLI, I. Efeito do cultivo da cana-de-açúcar na estabilidade de agregados e na condutividade hidráulica. Irriga, 10:116-122, 2005.

HORN, R. Aggregate characterization as compared to soil bulk properties. Soil Till. Res., 17:265-289, 1990. 
KLEIN, V.A.; LIBARDI, P.L. \& SILVA, A.P. Resistência mecânica do solo à penetração sob diferentes condições de densidade e teor de água. Eng. Agric., 19:45-54, 1998.

KLEIN, V.A. \& LIBARDI, P.L. Densidade e distribuição do diâmetro dos poros de um Latossolo Vermelho, sob diferentes sistemas de uso e manejo. R. Bras. Ci. Solo, 26:857-867, 2002.

KIEHL, E.J. Manual de edafologia. São Paulo; Ceres, 1979. $262 \mathrm{p}$.

PEDROTTI, A.; FERREIRA, M.M.; CURI, N.; SILVA, M.L.N.; LIMA, J.M. \& CARVALHO, R. Relação entre atributos físicos, mineralogia da fração argila e formas de alumínio no solo. R. Bras.Ci. Solo, 27:1-9, 2003.

RESENDE, M. Aplicações de conhecimentos pedológicos à conservação de solos. Inf. Agropec., 11:3-18, 1985.

SANCHEZ, P.A. Suelos del trópico: Características y manejo. San José, Instituto Interamericano de Cooperacion para la Agricultura, 1981. 645p.

SCHWERTMANN, U. \& HERBILLON, A.J. Some aspects of fertility associated with the mineralogy of highly weathered tropical soils. In: LAL, R. \& SANCHES, P.A. MYTHS AND SCIENCE OF SOILS OF THE TROPICS: OF AN INTERNATIONAL SYMPOSIUM Madison, 1992. Proceedings. Madison, American Society of Agronomy. USA: Soil Science Society of America, 1992. p.47-59.
SILVA, A.P. \& KAY, B.D. Estimating the least limiting water range of soils from properties and management. Soil Sci. Soc. Am. J., 61:877-883, 1997.

SILVA, M.L.N.; BLANCANEAUX, P.; CURI, N.; LIMA, J.M.; MARQUES, J.J.G.S.M. \& CARVALHO, A.M. Estabilidade e resistência de agregados de Latossolo Vermelho-Escuro cultivado com sucessão milho-adubo verde. Pesq. Agropec. Bras., 33:97-103, 1998.

SILVA, M.L.N.; CURI, N. \& BLANCANEAUX, P. Sistemas de manejo e qualidade estrutural de um Latossolo Roxo. Pesq. Agropec. Bras., 35:2485-2492, 2000.

SOUZA, Z.M. \& ALVES, M.C. Propriedades físicas e teor de matéria orgânica em um Latossolo Vermelho de cerrado sob diferentes usos e manejos. Acta Sci., 25:27-34, 2003.

TORMENA, C.A.; FRIEDRICH, R.; PINTRO, J.C.; COSTA, A.C.S. \& FIDALSKI, J. Propriedades físicas e taxa de estratificação de carbono orgânico num Latossolo Vermelho após dez anos sob dois sistemas de manejo. R. Bras. Ci. Solo, 28:1023-1031, 2004.

UEHARA, G. Acric properties and their significance to soil classification. In: INTERNATIONAL SOIL CLASSIFICATION WORKSHOP, 8., Rio de Janeiro, 1986. Proceedings. Rio de Janeiro, Embrapa/SNLCS, 1988. p.19-22.

VIEIRA, L.S.; SANTOS, P.C.T.C. \& VIEIRA, M.N.S. Solos: propriedade, classificação e manejo. Brasília, MEC/ ABEAS, 1988. p.53-61. (Programa Agricultura nos Trópicos) 